\title{
Social support received by the family of older patients in emergency department: A cross-sectional study
}

\author{
Jekaterina Demidenko*1, Pirkko Routasalo ${ }^{2}$, Mika Helminen ${ }^{1}$, Päivi Åstedt-Kurki ${ }^{1}$, Eija Paavilainen ${ }^{1}$, Tarja Suominen ${ }^{1}$ \\ ${ }^{1}$ Faculty of Social Sciences, University of Tampere, Tampere, Finland \\ ${ }^{2}$ University of Helsinki, Helsinki, Finland
}

Received: October 17, 2017

Accepted: November 23, $2017 \quad$ Online Published: December 5, 2017

DOI: $10.5430 / \mathrm{cns} . v 6 \mathrm{n} 2 \mathrm{p} 1$

URL: https://doi.org/10.5430/cns.v6n2p1

\begin{abstract}
Poor social support provided within health care settings may reduce patients' ability to manage disease. The presence of family members in emergency department (ED) may reduce the patient's need for health care and social services utilization. The aim of the study was to describe the social support received by family in the ED. A cross-sectional empirical study design was used. Convenience sample of 111 family members of home discharged older patients and of 93 nurses were recruited. The study was conducted at four Estonian hospitals. Data were collected by using social support scale of the Family Functioning, Health and Social Support (FAFHES). Family members and nurses both considered the social support available in EDs to be moderate. Nurses believed they provided higher levels of social support than the family members stated the family received. The differences were statistically significant. The older a nurse was, the less reinforcement, feedback, and affecting others for finding solutions was offered. A greater number of nurses working in the ED resulted in less social support. This study found differences of views between family members of older patients and nurses regarding the level of social support of the family. Nursing care provided in ED should be developed to be more supportive. To ensure more family-centred approach when providing nursing care, the administrative staff needs to consider whether an adequate number of nurses are working in the ED. The social support scale used was found to be applicable in ED environments.
\end{abstract}

Key Words: Emergency department, Family members, Nursing care, Older patients, Social support

\section{INTRODUCTION}

Social support refers to physical and psychosocial assistance provided to an individual by people close to him or her. ${ }^{[1]}$ According to Kahn, ${ }^{[2]}$ social support is understood as purposeful interaction between people that may involve one or more of the following components: affirmation, a process of reinforcing feedback and guiding others in finding appropriate solutions; concrete aid, including materials, money or time spent taking care of others; and emotional support, which may be understood as a feeling of safety, esteem, value, and respect. Social support within the nursing field is understood as an influential relationship between health care provider as nurse and health care user as family, where family is seen as identical member in a free and agreed climate. ${ }^{[3]}$

Poor health, the presence of chronic disease, and frequent use of health care services often prompt older patients to apply for social support. ${ }^{[4-6]}$ For these patients, social support networks often consist of health care professionals, family members, and partners. ${ }^{[7]}$

Higher scores in perceived social support, higher levels of

\footnotetext{
*Correspondence: Jekaterina Demidenko; Email: Demidenko.Jekaterina.X@student.uta.fi; Address: Faculty of Social Sciences, University of Tampere, Tampere, Lääkarinkatu 1, FI-33014, Finland.
} 
cognitive functioning, and increased daily living activities by older patients predict depression. ${ }^{[8,9]}$ Kaur et al. ${ }^{[10]}$ found that poor self-care in older patients was significantly related to the need for social support. However, married older patients needed less social support offered by health care professionals than those without a partner. ${ }^{[1]}$ According to urban Taiwanese older patients found that age, marital status, and education were generally related to the received social support. ${ }^{[6]}$ In a study conducted across seven European countries it was revealed that low levels of social support were associated with older patients' age and their psychological abuse. ${ }^{[4]}$ One cross-sectional study examined older patients and social support in relation to quality of life and found that older patients received social support mostly from family, friends, and other people close to them. ${ }^{[12]}$ Ha et al. ${ }^{[13]}$ investigated the relationship between health among older patients and social support provided by their family members. It was made clear that older patients' poor health was related to insufficient contact and interaction with friends and family members. ${ }^{[13]}$ Risk factors related to harmful outcomes among older patients discharged home from hospital care were lack of social support, low functional status, and needing to take a number of different medications. ${ }^{[14]}$

A recent study conducted within oncological settings revealed that poor social support provided by healthcare professionals may reduce patients' ability to manage disease. ${ }^{[15]}$ Older patients who arrived at the emergency department (ED) in an ambulance had received less social support than those who used their own transport. ${ }^{[16]}$

Older patients who used social care services were found to be greater hospital care utilizers compared to those who did not. ${ }^{[17]}$ Older people who received care at nursing homes had lower proportions of emergency service utilization than older patients who received care at home. ${ }^{[17]}$ Parsons et al. ${ }^{[18]}$ and Naughton et al. ${ }^{[19]}$ suggested that complex geriatric assessments, including identifying social needs and evaluating physical function, may improve health outcomes of older patients. Appropriate guidelines aimed to regulate best practices may result in better care of older patients in EDs. ${ }^{[20]}$ Accessibility of support in an ED worsened when the amount of patients increased and the duties of nurses expanded. ${ }^{[21]}$

Social support has been investigated in relation to several clinical conditions like mental disorders, ${ }^{[22]}$ cancer, ${ }^{[15]}$ and heart disease, ${ }^{[3]}$ and was found to be sufficient, but ED settings not been researched. Earlier study has shown associations between background factors such as marital status and education to social support. Those patients who were single reported greater need for social support from health care professionals than those who were married. ${ }^{[23]}$ Those with lower education experienced more social support from family, colleagues, or people close to them than people with higher education. ${ }^{[24]}$ The current study is centered on three subareas of social support, affirmation, concrete aid, and affect, ${ }^{[3]}$ that were found to be crucial in maintaining cognitive behavior of older patients. ${ }^{[25]}$

\subsection{Background}

Affirmation, one of the subareas of social support, is a process of reinforcing feedback and guiding others in finding appropriate solutions. ${ }^{[3]}$ Swedish ED nurses acknowledged the need to show empathy and to be aware of older patients' social environments in order to provide appropriate nursing care in the ED. ${ }^{[26]}$ In one Finnish study, patients with previous hospital experience demonstrated greater motivation for self-care, which provided them with a better ability to cope with their condition. ${ }^{[27]}$ A study by Flynn et al. ${ }^{[28]}$ showed that decision support and related interventions were associated with an increase in patient knowledge, decision-making, desire for participation, and satisfaction with care received.

Another subarea of social support is concrete aid, including materials, money, or time spent taking care of others. ${ }^{[3]}$ Support for hospital patients and associated factors were examined by Mattila et al., ${ }^{[21]}$ who found that patients were most dissatisfied with information provided regarding significance of lifestyles to health and access to written information. A Finnish study that investigated the experiences of family members of older patients in EDs revealed that family members wanted to be involved in the care process. ${ }^{[29]}$

After discharge, older patients often continue care at home. Health care professionals may help families and older patients by creating activity plans related to older patients' ability to cope with health problems at home, which reinforces social support. ${ }^{[30]}$ The findings of Leikkola et al. ${ }^{[27]}$ highlight the importance of patient education and meeting families' information needs regarding providing in-home support. Older patients stated that adequate information received upon discharge helped support their coping at home. ${ }^{[27]}$ However, Themessel-Huber et al. ${ }^{[31]}$ found that older patients are often unlikely to trust available services, and instead rely on their family members. They described older patients waiting throughout the day for family members to return from work to help them. ${ }^{[31]}$

Affect, the third subarea of social support, is understood as a feeling of safety, esteem, value, or respect. ${ }^{[3]}$ In a study conducted within ED settings, older patients felt uncared for and that their needs were not taken into account by nurses. ${ }^{[32]}$ According to Finnish patients' experiences, nurses were too occupied to be involved in patients' care planning. ${ }^{[21]}$

Themessel-Huber and colleagues ${ }^{[31]}$ noted that social sup- 
port is important to both patients and their families, and is an essential factor of quality nursing care. Older patients tend to be higher users of both health care and social services. ${ }^{[31]}$ In European countries, hospital stays have been reduced, and the focus of treatment is at-home care. Some older patients avoid hospitals, and only seek help after their condition has seriously deteriorated. This has created the need to provide more comprehensive care for older patients in an ED before they are discharged home. ${ }^{[31]}$ The current study provides information on social support provided by nurses to families in EDs. This cross-sectional study evaluates the current situation in four Estonian EDs in order to indicate the need for intervention and improve nursing care for older patients and their family.

\subsection{Aim of the study}

The aim of this study was to describe the social support received by older patients' families and to present the differences between the social support received by families and provided by nurses in EDs. The following questions were set out:

- How do family members describe the social support received by family from nurses in the EDs?

- How do nurses describe the social support received by family in the EDs?

- How does the social support described by family members differ from that described by the nurses?

\section{METHOD}

\subsection{Research design and sample}

This cross-sectional study was conducted at four Estonian EDs. Data were collected from two regional and two central hospitals over five months in 2014. In Estonia, regional hospitals are the larger health care providers, as compared to central or general hospitals. On an average, there were amount of 220 patients treated in one regional hospital per day in 2014 , as compared to general hospital where number of 229 patients were treated per month. ${ }^{\text {[33] }}$

\subsection{Sample and data collection}

A convenience sample of family members aged $\geq 18$ $(\mathrm{n}=111)$ and ED nurses $(\mathrm{n}=93)$ was taken. The first stage concentrated on family members' perceptions of social support received in the ED. A total of 367 questionnaires were distributed by the researcher and ED nurses to family members of older patients that were discharged home. The questionnaire was available in both Estonian and Russian. Respondents were asked to describe their view of the social support received by family during a recent ED stay, and how the family responded to that support. Family members of home discharged older patients were asked to mail completed questionnaires to the researcher within two weeks after the date of discharge. Eight meetings were conducted with ED nurses and administrative staff to improve the data collection process, and informative posters were placed in the EDs. As a result, $111(30 \%)$ questionnaires were returned to the researcher.

At the second stage, all nurses at the four participating EDs were asked to participate, thus, 144 questionnaires were distributed. The nurses answered questions regarding the social support offered to family of older patient during an ED visit, and how the family responded. Nurses received reminders to complete the questionnaire. At each ED, there were closed boxes for completed questionnaires. Ultimately 93 (65\%) completed questionnaires were returned.

\subsection{Instrument}

To measure social support, this study used adapted version of the Family Functioning, Health and Social Support (FAFHES) instrument with 20 items. $^{[3]}$ The original Finnish version was previously validated by Åstedt-Kurki et al., ${ }^{[3]}$ but not in an ED setting. Therefore, the FAFHES was modified for this new environment. The final scale consisted of 20 items, as describing affirmation (6), concrete aid (6), and affect (8). One item describing affirmation in the original version was reassigned to the subarea describing concrete aid. Both questionnaires for family members and nurses were based on the original scale. Due to the high percentage of Russians living in Estonia (30\%), the questionnaire was translated from English into both Estonian and Russian. ${ }^{[34]}$

Internal consistency was measured by Cronbach alphas. ${ }^{[35]}$ The reliabilities of the FAFHES are presented in Table 1. For the entire scale of social support, Cronbach $\alpha$ was 0.90 for family members, and for nurses 0.95 .

A six-point Likert scale was used for expressing respondent agreement with statements describing social support (from 1 = definitely disagree to $6=$ definitely agree). Social support was considered to be poor if the mean was 1.00-2.75; moderate if it was 2.76-4.50; and good if it was 4.51-6.00.

The instrument was piloted in family members of discharged older patients $(n=7)$ and ED nurses $(n=18)$ in the EDs of three general hospitals. No questions were excluded.

\subsection{Demographic variables}

The demographic characteristics of family members included gender, age, marital status, social status, highest education, relationship to the older patient, and whether the family member lived with the patient. Family members were asked to assess their own health condition at the moment of the data 
collection, their own need for help in daily life, and length of the time spent in the ED. They were also asked to provide information on the older patients, including gender, age, marital status, highest education, health problems, the amount of help they needed in daily life before the ED visit, the day of the week on which the ED was visited, the mode of transport used to reach the ED, and number of previous visits to the ED due to the same health problem during one year. The functional status of older patients at discharge was evaluated using seven questions of published instrument of Rowland et al. ${ }^{[36]}$ Four or more positive answers indicated an older patient considered to be at risk for readmission. ${ }^{[36]}$
The demographic characteristics of nurses included gender, age, marital status, highest professional education, length of time spent working in health care, emergency medicine and the current ED, the number of nurses working in the ED, the number of older patients visiting the ED during one shift, the primary reason for the patient's ED visit, the day of the week older patients most often visit the ED, older patients' need of help in daily life before the ED visit, how many hours family members spend in the ED with older patients, the type of transport older patients use to arrive at the ED, and the functional status of older patients at discharge.

Table 1. The reliabilities of the FAFHES

\begin{tabular}{|c|c|c|}
\hline Content of the items & $\begin{array}{l}\text { Family members } \\
\alpha\end{array}$ & $\begin{array}{l}\text { Nurses } \\
\alpha\end{array}$ \\
\hline Social support (number of items) & 0.90 & 0.95 \\
\hline $\begin{array}{l}\text { Affirmation (6) } \\
\text { - Explanation related to involvement in care planning } \\
\text { - Explanation related to care } \\
\text { - Counselling related to matters of care } \\
\text { - Discussions related to course of illness } \\
\text { - Discussions related to older patients' condition during ED stay } \\
\text { - Discussions related to progress of care }\end{array}$ & 0.92 & 0.86 \\
\hline $\begin{array}{l}\text { Concrete aid (6) } \\
\text { - Discussions related to treatment options } \\
\text { - Explanation about older patient's diet } \\
\text { - Explanation related to type of exercises older patient can take } \\
\text { - Information regarding older patient's mental exertion } \\
\text { - Information regarding risks of bathing } \\
\text { - Information regarding how illness affects sexual life }\end{array}$ & 0.61 & 0.91 \\
\hline $\begin{array}{l}\text { Affect (8) } \\
\text { - Family involvement in the patient's care } \\
\text { - Space for expressing feelings } \\
\text { - Showing compassion for family } \\
\text { - Feedback related to family involvement in care } \\
\text { - Showing interest in family affairs } \\
\text { - Showing appreciation for family involvement in the patient's care } \\
\text { - Showing consideration for the well-being of family } \\
\text { - Showing interest in family coping with aftercare }\end{array}$ & 0.88 & 0.93 \\
\hline
\end{tabular}

\subsection{Data analysis}

The data were analyzed using Statistical Package for the Social Sciences (SPSS) 23.0. Descriptive statistics were used to describe basic features of the data. A $t$-test was used to compare group means. The Wilcoxon signed-rank test was used to assess differences between paired measurements. The Spearman rank correlation was used to measure the degree of association between two variables. A $p$-value of $<.05$ was considered statistically significant.

\subsection{Ethical considerations}

Ethical approval (NR 193) for the current study was obtained from the Tallinn Medical Research Ethics Committee. Informed consent was considered when family members and nurses after received research related information returned the questionnaires. Permission to use and modify FAFHES was gathered from all copyright holders. Study permissions were obtained from the managers of the EDs or appropriate clinics. Anonymity of the respondents was guaranteed. ${ }^{[35]}$ 
Returning the questionnaires by post was free for the respondents. The respondents were able to contact the researcher if needed. ${ }^{[37]}$

\section{RESUlts}

A total of 111 family members enrolled in the study. The majority were female $(73 \%, \mathrm{n}=81)$, the age range was 19-79 years $(M=47.64)$, and $73 \%(n=81)$ were married. Most $(54 \%, \mathrm{n}=60)$ reported school as their highest education, and $74 \%(\mathrm{n}=82)$ had a job. When the relationship to the older patient was examined, it was found that $41 \%(n=45)$ were children and $43 \%(n=48)$ had a relationship to the patient other than that of a spouse or a child. Total of $62 \%(n=69)$ did not live with the patient. Finally, 54\% $(n=64)$ rated their own health as "good".

According to family members, the older patients visited the ED due to musculoskeletal $(30 \%, \mathrm{n}=33)$, abdominal $(18 \%$, $\mathrm{n}=20)$, or cardiovascular $(16 \%, \mathrm{n}=18)$ problems. Adverse drug reactions accounted for $11 \%(n=13)$ of the visits. Most family members presented with older patients on weekdays $(70 \%, \mathrm{n}=78)$. Over half $(66 \%, \mathrm{n}=73)$ of the patients used a method of transport other than an ambulance service. For $70 \%(\mathrm{n}=78)$ of family members, the time spent in the ED was up to three hours. The majority of respondents $(70 \%, \mathrm{n}$ $=78$ ) stated that the older patient had not been admitted to the ED for the same health problem in the past year.

Over half $(55 \%, \mathrm{n}=61)$ the older patients were female, with an age range of 65-92 ( $\mathrm{M}=75.04)$; more than half $(54 \%$, $\mathrm{n}=60)$ were single, and $81 \%(\mathrm{n}=90)$ had graduated from secondary school. A risk of readmission was found in $41 \%$ $(n=45)$ of the older patients, while four or more positive answers indicated that older patient was at risk for readmission.

A total of 93 nurses participated in the study. The majority $(92 \%, \mathrm{n}=86)$ were female and married $(73 \%, \mathrm{n}=68)$; their age range was $21-60(\mathrm{M}=35.16)$. Most $(84 \%, \mathrm{n}=$ 78) reported registered nurse as their highest professional education. Over half $(62 \%, \mathrm{n}=58)$ had over five years work experience in health care, slightly more than half $(53 \%$, $\mathrm{n}=49$ ) in emergency medicine. However, only $53 \%$ $(n=49)$ had worked at current ED for over five years. Nurses stated that older patients visited the ED due to cardiovascular problems $(39 \%, \mathrm{n}=36)$, musculoskeletal problems $(25 \%$, $\mathrm{n}=23)$, or poor health $(16 \%, \mathrm{n}=15)$. More than half $(60 \%, \mathrm{n}=64)$ stated that older patients did not prefer to visit the ED on a certain day of the week. Many nurses $(56 \%$, $\mathrm{n}=52$ ) claimed that older patients arrived by ambulance service. According to the nurses $(51 \%, \mathrm{n}=47)$, family mem- bers spent over three hours in the ED. Only 27\% $(n=25)$ of ED nurses believed that older patients were at risk for readmission.

\subsection{Social support evaluated by family members}

The family members perceived the level of social support family received during the older patient's ED stay as moderate $(\mathrm{M}=3.58 ; S D=0.97)$.

Affirmation, the subarea of social support that involves reinforcing, feedback and affecting others for finding solutions, was found to be at moderate level in the ED $(\mathrm{M}=3.68$; $S D=1.11)$. There was a statistically significant difference between affirmation of the family member and living together with older patient who visited ED ( $p=.027)$. Concrete aid, the subarea of social support understood as resources used for taking care of others, was evaluated at moderate level in the ED $(\mathrm{M}=3.44 ; S D=1.09)$. There was a statistically significant difference between concrete aid and age of older patient $(p=.013)$. Affect, the subarea of social support affecting feelings of safety, esteem, value, and respect, was also evaluated at moderate level in the ED $(\mathrm{M}=3.62$; $S D=1.13)$.

\subsection{Social support evaluated by nurses}

Nurses rated the social support provided for families of patients in the ED at moderate level $(\mathrm{M}=3.93 ; S D=0.83)$. The number of nurses working in the ED and level of social support ( $p=.049$ ) were negatively correlated: the more nurses working in the ED, the less social support they provided.

Affirmation was evaluated at moderate level $(\mathrm{M}=4.02$; $S D=0.94)$. There was weak negative correlation identified between a nurse's age and affirmation $(p=.047)$. The older the nurse, the less he or she offered reinforcement, feedback, and influenced others. Concrete aid was evaluated at moderate level $(\mathrm{M}=3.79 ; S D=0.94)$, as was affect $(\mathrm{M}=3.97 ; S D=0.97)$.

\subsection{The differences between descriptions of social sup- port received by family and offered by nurses}

Nurses reported that they had offered social support to families of older patients at a higher level than family members reported the family had received $(p=.006)$ in the ED. The differences between the social support received by families and provided by nurses in EDs are presented in Table 2. Within all subareas of social support, the nurses believed they had provided more social support than family members reported the family received. 
Table 2. The differences between the social support received by families and provided by nurses in EDs

\begin{tabular}{llll}
\hline & Family members & Nurses & p-value \\
& M $(\boldsymbol{S D})$ & M $(\boldsymbol{S D})$ & .006 \\
Social support (number of items) & $3.58(0.97)$ & $3.93(0.83)$ & .016 \\
Affirmation (6) & $3.68(1.11)$ & $4.02(0.94)$ & .013 \\
Concrete aid (6) & $3.44(1.09)$ & $3.79(0.94)$ & .016 \\
Affect (8) & $3.62(1.13)$ & $3.97(0.97)$ & \\
\hline
\end{tabular}

\section{DiscuSsion}

In this study, social support perceived by family from nurses was found to be moderate. The results show that nurses believed they provided more social support than family members described family received. The potential consequences of these results are supported by the following findings. Ha et al. ${ }^{[13]}$ stated that insufficient social support is related to the poor health of the older patient. Poor social support provided by healthcare professionals may reduce patients' ability to cope with illness. ${ }^{[15]} \mathrm{A}$ lack of social support is considered a risk factor of for harmful outcomes among older patients discharged home. ${ }^{[14]}$ This may lead to an increase in health care utilization and related costs. Frequent use of health care services is one reason older patients apply for social support, ${ }^{[4-6]}$ and should be considered when providing ED care for this population.

It was found that one subarea of social support was associated with older patients' age. This finding is supported by Dai et al., ${ }^{[6]}$ who identified that few demographic characteristics as age, marital status, and education were generally related to the received social support. In addition, living together with older patient who visited ED was associated with another subarea of social support. This result is confirmed by $\mathrm{Ha}$ et al., ${ }^{[13]}$ who presented that older patients' poor health was related to insufficient contact and interaction with friends and family members. This may be suggested, that if the older patient lives with a family member the better social support may be perceived.

According to $41 \%$ of family members, older patients were at risk for readmission at discharge. Readmissions may be reduced by providing a comprehensive geriatric assessment that evaluates both physical function and the need for social care. ${ }^{[18,19,31]}$ In cases where older patients are at risk for readmission, related crucial information should be described in a medical report or referrals directed to the primary care level regarding after-care issues. This idea is supported by Naughton et al., ${ }^{[19]}$ who highlighted the need for complete referrals containing sufficient information. It was found that older patients were discharged from the ED with inadequate information on their referral sheets. ${ }^{[19]}$

In addition, over half the nurses claimed that older patients 6 were transported to the ED by an ambulance service. It would seem that patients arrived by ambulance might lead to more social support. This can lead to the findings revealed from the study by Moonesar et al., ${ }^{[16]}$ in which older people who arrived at the ED via ambulance were found to have significantly lower social support than those who used their own transport. The results specific to the use of transport lead us to the fact that social support in ED would have to be more assessed and assured.

Older patients who live alone are more likely to visit the ED and may have a greater need for social services than those who live with their family. ${ }^{[23]}$ In the current study, more than half the family members reported that they did not live with the older patient. According to Banbury et al. ${ }^{[7]}$ family members are crucial parts of older patients' social networks.

We were surprised to find that the more nurses worked in an ED, the less social support was provided. Even though the number of nurses increased, the number of patients increased even more. It would seem that an increased number of nurses would lessen the workload and allow them to focus more time on patients. Results of our study are supported by Finnish researcher Mattila et al., ${ }^{[21]}$ who found that accessibility of support worsened when the number of emergency patients increased and duties of nurses expanded. However, we could consider that there may be some other confounding factors. Here, it is clear that the hospital administration must pay special attention to human resource planning and management in order to ensure there are a sufficient number of nurses providing family-centered nursing care. Efficiency increases when resources are utilized in the best way.

The older the nurse was, the less affirmation was provided. It may be assumed that older, more experienced nurses might provide better care, and share knowledge with others - that has been disproved. This result may be due to the nurse having too many duties. There is not enough time to identify the social needs of the entire family, and which is why patient-centered approach has been neglected.

\section{Conclusions}

Nurses reported that they offered greater social support than family members stated the family had received. Despite 
this, social support for family was found to be moderate by both family members and nurses. In order to ensure disease management and promote the patient's ability to cope at home, nurses must ask the family presenting in the ED for knowledge about the patient's social network. To guarantee a patient-centered approach when providing nursing care, the administrative staff needs to consider whether an adequate number of nurses are working in the ED.

Further studies are needed to advance our understanding of social support in EDs. Additional studies regarding the type of social support or services a family presenting in the ED requires would be beneficial. It is essential to investigate whether the role of ED nurses is clearly defined, as a lack of definition may explain why this study found social support to be at moderate level. Social support scale of the FAFHES used in this study was found to be applicable in ED environments. Further usage of the instrument in EDs should be considered.

\section{Limitations}

Some limitations of our study may have affected the results. The study was designed to collect data from at least 367 family members, but was completed and analyzed with 111 family members due to challenging data collection and fixed period. A larger sample size and higher response rate would allow better comparison of the results. ${ }^{[35]}$ In addition, family members involved in the study participated once. A control group was not used aimed to investigate whether the situation has been improved over the time. We did not check whether the same older patients were readmitted later. Finally, there is lack of literature describing the experiences of both family members of older patients and nurses regarding social support in EDs, which made comparing results with previously conducted studies challenging.

\section{ACKNOWLEDGEMENTS}

The authors would like to thank family members of discharged home older patients and ED nurses who participated in the study.

\section{CONFLicts OF InTEREST Disclosure}

The authors declare they have no conflicts of interest.

\section{REFERENCES}

[1] Barrera M. Distinctions between social support concepts, measures, and models. Am J Community Psychol. 1986 Aug; 14(4): 413-45. https://doi.org/10.1007/BF00922627

[2] Kahn RL. Aging and social support. In: Riley MW. (Ed.). Aging from birth to death: interdisciplinary perspectives. Boulder, CO: Westview; 1979. 77-91 p.

[3] Åstedt-Kurki P, Tarkka M, Rikala M, et al. Further testing of a family nursing instrument (FAFHES). Int J Nurs Stud. 2009 Mar; 46(3): 350-59. https://doi.org/10.1016/j.ijnurstu.2008.01.0

[4] Melchiorre MG, Chiatti C, Lamura G, et al. Social support, socioeconomic status, health and abuse among older people in seven european countries. PLoS ONE. 2013 Jan; 8(1): e54856. https : //doi.org/10.1371/journal.pone.0054856

[5] Burzynska M, Bryla M, Bryla P, et al. Factors determining the use of social support services among elderly people living in a city environment in Poland. Health Soc Care Community. 2016 Nov; 24(6): 758-68. https://doi.org/10.1111/hsc. 12259

[6] Dai Y, Zhang CY, Zhang BQ, et al. Social support and the self-rated health of older people: a comparative study in Tainan Taiwan and Fuzhou Fujian province. Medicine (Baltimore). 2016 Jun; 95(24): e3881. https://doi.org/10.1097/MD.0000000000003881

[7] Banbury A, Chamberlain D, Nancarrow S, et al. Can videoconferencing affect older people's engagement and perception of their social support in long-term conditions management: a social network analysis from the Telehealth. Health Soc Care Community. 2017 May; 25(3): 938-50. https://doi.org/10.1111/hsc.12382

[8] Bozo Ö, Toksabay NE, Kürüm O. Activities of daily living, depression, and social support among elderly turkish people. J Psychol.
2009 Mar; 143(2): 193-206. https://doi.org/10.3200/JRLP $.143 .2 .193-206$

[9] Lee JE, Kahana B, Kahana E. Social support and cognitive functioning as resources for elderly persons with chronic arthritis pain. Aging Ment Health. 2016 Mar; 20(4): 370-79. https ://doi .org/10.1 080/13607863.2015.1013920

[10] Kaur N, Kaur J, Thapar K. Perceived self care deficit and social support system among elderly. Nurs Midwifery Res J. 2015 Jul; 11(3): 112-19.

[11] Lien CY, Lin HR, Kuo IT, et al. Perceived uncertainty, social support and psychological adjustment in older patients with cancer being treated with surgery. J Clin Nurs. 2009 Aug; 18(16): 2311-19. https://doi.org/10.1111/j.1365-2702.2008.02549.x

[12] Kwan P, Ali A, Deuri SP. Psychiatric morbidity, quality of life, and perceived social support among elderly population: a communitybased study. Open J Psychiatry Allied Sci. 2016 Jan-Jun; 7(1): 31-5. https://doi.org/10.5958/2394-2061.2016.00007.0

[13] Ha JH, Kahng SK, Choi N. Reciprocal effects between health and social support in older adults' relationships with their children and friends. Res Aging. 2015 Oct; 39(2): 300-21. https: //doi.org/10.1177/0164027515611182

[14] Preyde M, Brassard K. Evidence-based risk factors for adverse health outcomes in older patients after discharge home and assessment tools: a systematic review. J Evid Based Soc Work. 2011 Oct; 8(5): 445-68. https://doi.org/10.1080/15433714.2011.542330

[15] Suwankhong D, Liamputtong P. Social support and women living with breast cancer in the south of Thailand. J Nurs Scholarsh. 2016 Jan; 48(1): 39-47. https : //doi . org/10.1111/jnu. 12179

[16] Moonesar R, Sammy I, Nunes P, et al. Social support in older people: lessons from a developing country. Qual Life Res. 2016 Jan; 25(1): 
233-36. PMid: 26091584. https://doi.org/10.1007/s11136

-015-1053-0

[17] Bardsley M, Georghiou T, Chassin L, et al. Overlap of hospital use and social care in older people in England. J Health Serv Res Policy. 2012 Jul; 17(3): 133-39. https ://doi .org/10.1258/JHSRP . 20 11.010171

[18] Parsons M, Senior H, Chen XMH, et al. Assessment without action; a randomised evaluation of the interRAI home care compared to a national assessment tool on identification of needs and service provision for older people in New Zealand. Health Soc Care Community. 2013 Sep; 21(5): 536-44. https://doi.org/10.1111/hsc. 12045

[19] Naughton C, McGrath E, Drennan J, et al. The profile and follow-up of patients who attend the emergency department following a fall. Int Emerg Nurs. 2012 Oct; 20(4): 243-50. https://doi .org/10.101 6/j.ienj.2011.07.005

[20] Carpenter CR, Bromley M, Caterino JM, et al. Optimal older adult emergency care: introducing multidisciplinary geriatric emergency guidelines from the American College of Emergency Physicians, American Geriatrics Society, Emergency Nurses Association, and Society for Academic Emergency Medicine. J Am Geriatr Soc. 2014 Jul; 62(7): 1360-63. https://doi .org/10.1111/jgs. 12883

[21] Mattila E, Kaunonen M, Aalto P, et al. Support for hospital patients and associated factors. Scand J Caring Sci. 2010 Dec; 24(4): 734-45. https://doi.org/10.1111/j.1471-6712.2010.00771.x

[22] Wang X, Cai L, Qian J, et al. Social support moderates stress effects on depression. Int J Ment Health Syst. 2014 Nov; 8: 41 https://doi.org/10.1186/1752-4458-8-41

[23] Hastings SN, George LK, Fillenbaum GG, et al. Does lack of social support lead to more ED visits for older adults? Am J Emerg Med. 2008 May; 26(4): 454-61. https://doi.org/10.1016/j.ajem .2007 .07 .005

[24] Nordgren L, Söderlund A. Received and needed social support in relation to sociodemographic and socio-economic factors in a population of people on sick leave due to heart failure. ESC Heart Fail. 2017 Feb; 4(1): 46-55. https://doi .org/10.1002/ehf2.12121

[25] Green AF, Rebok G, Lyketsos CG. Influence of social network characteristics on cognitive and functional status with aging. Int J Geriatr Psychiatry. 2008 Sep; 23(9): 972-78. https ://doi.org/10.100 2/gps. 2023

[26] Kihlgren AL, Nilsson M, Sørlie V. Caring for older patients at an emergency department - emergency nurses' reasoning. J Clin Nurs. 2005 May; 14(5): 601-8. https ://doi .org/10.1111/j.1365-2 $702.2004 .01104 . x$
[27] Leikkola P, Helminen M, Paavilainen E, et al. Staff support for back surgical patients and family members. Does it improve coping at home? Orthop Nurs. 2014 Nov-Dec; 33(6): 352-58. https : //doi.org/10.1097/NOR.0000000000000099

[28] Flynn D, Knoedler MA, Hess EP, et al. Engaging patients in health care decisions in the emergency department through shared decision-making: a systematic review. Acad Emerg Med. 2012 Aug; 19(8): 959-67. https://doi.org/10.1111/j.1553-271 2.2012.01414.x

[29] Nikki N, Lepistö S, Paavilainen E. Experiences of family members of elderly patients in the emergency department: a qualitative study. Int Emerg Nurs. 2012 Oct; 20(4): 193-200. https: //doi.org/10.1016/j.ienj.2012.08.003

[30] Tao H, McRoy S. Caring for and keeping the elderly in their homes. Chin Nurs Res. 2015 Jun-Sep; 2(2-3): 31-4. https ://doi .org/10 $.1016 / \mathrm{j}$.cnre. 2015.08 .002

[31] Themessel-Huber M, Hubbard G, Munro P. Frail older people's experiences and use of health and social care services. J Nurs Manag. 2007 Mar; 15(2): 222-29. https://doi.org/10.1111/j.1365 $-2834.2007 .00726 . x$

[32] McCabe JJ, Kennelly SP. Acute care of older patients in the emergency department: strategies to improve patient outcomes. Emerg Med. 2015 Sep; 7: 45-54. https://doi.org/10.2147/OAEM.S 69974

[33] The public inquiry: Periodic specialist care [Internet]. Estonian Health Insurance Fund. 2014 [cited 10 October 2017]. Available from: www.haigekassa.ee

[34] Maneesriwongul W, Dixon JK. Instrument translation process: a methods review. J Adv Nurs. 2004 Oct; 48(2): 175-86. PMid: 15369498. https://doi.org/10.1111/j.1365-2648.2004.0 $3185 . x$

[35] Polit DF, Beck CT. Nursing Research. Generating and assessing evidence for nursing practise, 8th edition. Philadelphia, USA: Lippincott Williams \& Wilkins; 2008. 180, 341, 455 p.

[36] Rowland K, Maitra AK, Richardson DA, et al. The discharge of elderly patients from an accident and emergency department: functional changes and risk of readmission. Age Ageing. 1990 Nov; 19(6): 415-18. PMid: 2285010. https://doi.org/10.1093/ageing/1 9.6.415

[37] Declaration of Helsinki - ethical principles for medical research involving human subjects [Internet]. World Medical Association; 2013 [cited 10 October 2017]. Available from: http://www.wma.net/ en/30publications/10policies/b3/ 